\title{
Use of an Endobronchial Blocker and Selective Lung Ventilation to Aid Surgical Removal of a Lung Lobe Abscess in a Dog
}

\author{
Carl Bradbrook, ${ }^{1}$ Louise Clark, ${ }^{1}$ and Martina Mosing ${ }^{2}$ \\ ${ }^{1}$ Davies Veterinary Specialists, Manor Farm Business Park, Higham Gobion, Hitchin SG5 3HR, UK \\ ${ }^{2}$ Department of Anaesthesia, Vetsuisse Faculty, University of Zurich, Winterthurerstrasse 260, 8057 Zurich, Switzerland
}

Correspondence should be addressed to Carl Bradbrook, carlbradbrook@gmail.com

Received 15 December 2011; Accepted 25 January 2012

Academic Editors: K. K. Adamama-Moraitou and C. Hyun

Copyright ( $) 2012$ Carl Bradbrook et al. This is an open access article distributed under the Creative Commons Attribution License, which permits unrestricted use, distribution, and reproduction in any medium, provided the original work is properly cited.

\begin{abstract}
This paper documents use of an endobronchial blocker (EBB) to achieve selective lung ventilation (SLV) for the purpose of lung lobectomy with thoracoscopy. A 3-year-old female neutered Labrador Retriever, body mass of $18.5 \mathrm{~kg}$, was presented for exploratory thoracoscopy. Acepromazine and methadone were administered as premedication, and anaesthesia was induced with propofol and maintained with isoflurane in $100 \%$ oxygen and continuous infusions of fentanyl and lidocaine. Mechanical ventilation of the dog's lungs was performed prior to placement of an Arndt EBB caudal to the right cranial bronchus to allow SLV. Successful SLV was achieved with this technique, allowing continued inflation of the right cranial lobe. A reduction in the arterial partial pressure of oxygen to fractional inspired oxygen ratio $\left(\mathrm{PaO}_{2}: \mathrm{FiO}_{2}\right)$ of 444 to 306 occurred after placement of the EBB, with no change in monitored cardiopulmonary variables. F-shunt increased from $17.4 \%$ to $23.7 \%$ with a reduction in oxygen content $\left(\mathrm{CaO}_{2}\right)$ of 20.0 to $18.7 \mathrm{mg} \mathrm{dL}^{-1}$, remaining within the physiologic range. Due to lung adhesions to the diaphragm, conversion to thoracotomy was required for completion of the procedure. This technique is challenging to perform in the dog. Arterial blood gas analysis should be performed to allow adequate monitoring of ventilation.
\end{abstract}

\section{Introduction}

Thoracoscopic investigation of lung pathology is becoming a more widely used technique [1] with several advantages over the standard approach of lateral thoracotomy or sternotomy. Reduced requirement for analgesia postthoracoscopy compared to thoracotomy is evident in the human literature and has also been shown in dogs [2]. This may be due to the absence of requirement for rib retraction and a smaller incision when thoracoscopy is used.

To aid visualisation of structures within the thorax with an effectively closed chest, collapse of one lung or lung lobes is required by the surgeon. The use of either one lung ventilation (OLV) by placement of a double lumen endobronchial tube (DLT) [3], EZ-blocker [4], or an endobronchial blocker (EBB) $[5,6]$ placed proximal to the area of surgical interest are reported in humans and experimental dogs. In human anaesthesia, selective lung ventilation is reported for blocking specific lung lobes, especially in trauma cases, but OLV is still used more commonly [7]. Currently, OLV has been performed in the dog with an EBB $[5,6]$, an endobronchial tube [8], and a DLT [3]. There are, however, no case reports of selective lung ventilation (SLV) in the literature that the authors are aware of.

This case report describes the clinical use of an EBB in a dog and the problems encountered whilst selectively blocking the caudal part of the right lung.

\section{Case History}

A 3-year-old female neutered Labrador Retriever with a body mass of $18.5 \mathrm{~kg}$ was presented for investigation of recurrent episodes of coughing, lethargy, and exercise intolerance. The dog had presented twice previously and on both occasions 
undergone general anaesthesia for computed tomography (CT) of the thorax. Changes between the subsequent CT scans had been suggestive of a migrating foreign body and revealed evidence of consolidation of the right caudal lung lobe. No improvement in this area of consolidation had been evident with antimicrobial therapy, and a decision was made to perform an exploratory thoracoscopy.

Clinical examination revealed a heart rate (HR) of 140 beats per minute (bpm) with a grade II out of VI left side systolic murmur, point of maximum intensity over the mitral valve. Peripheral pulses were strong and regular. Respiratory rate $\left(f_{R}\right)$ was 16 breaths per minute with no increased effort. Auscultation revealed an area of dull lung sounds caudally on the right side of the thorax.

Echocardiography revealed a trivial mitral and tricuspid valve regurgitation, good systolic function, and no evidence of endocarditis.

Haematology and serum biochemistry were unremarkable.

2.1. Anaesthetic Technique. Preanaesthetic medication consisted of acepromazine (ACP $2 \mathrm{mg} \mathrm{mL}^{-1}$; Novartis $\mathrm{AH}$, UK) $0.01 \mathrm{mg} \mathrm{kg}^{-1}$ and methadone (Methadone; Martindales, UK) $0.3 \mathrm{mg} \mathrm{kg}^{-1}$ given by the intramuscular route (IM). After preoxygenation, anaesthesia was induced with propofol $5.4 \mathrm{mg} \mathrm{kg}^{-1}$ (Propoflo; Abbott Animal Health, UK). The trachea was intubated with a $10 \mathrm{~mm}$ cuffed endotracheal tube, attached to a circle breathing system, and the lungs mechanically ventilated with intermittent-positive pressure ventilation (IPPV). Isoflurane was vaporised in 100\% oxygen, and vaporiser settings were adjusted accordingly to maintain surgical depth of anaesthesia. IPPV was initially performed with a ventiPAC (Smiths Medical Pneupac, USA) volume/flowregulated ventilator and in theatre with a Cato edition (Drager Medical AG \& Co., Germany) volume-controlled ventilator. Initial ventilator settings was $f_{R} 15 \mathrm{bpm}$, tidal volume $\left(V_{T}\right) 185 \mathrm{~mL}$, resulting in a peak inspiratory pressure (PIP) of $14 \mathrm{~cm} \mathrm{H}_{2} \mathrm{O}$.

Monitoring consisted of percentage haemoglobin saturation with oxygen $\left(\mathrm{SpO}_{2}, \%\right)$, end tidal partial pressure of carbon dioxide $\left(\mathrm{PE}^{\prime} \mathrm{CO}_{2}\right)$, body temperature $\left({ }^{\circ} \mathrm{C}\right)$, and lead II ECG (Datex Ohmeda S/5; GE Healthcare, UK). A 20-gauge catheter (Jelco; Smiths Medical, USA) was placed percutaneously into the left dorsalis pedis artery for arterial blood gas sampling and invasive blood pressure measurement (IBP). A $12 \mathrm{fr}$ central venous catheter (Arrow International Inc., USA) was placed into the right jugular vein using the Seldinger technique to provide access for central venous pressure (CVP) measurement and fluid administration.

Fluid therapy consisted of Hartmanns solution (No. 11; Aquapharm, UK), $10 \mathrm{~mL} \mathrm{~kg}^{-1}$ hour $^{-1}$ intravenously. Other drugs administered were amoxicillin and clavulanic acid (Augmentin; GlaxoSmithKline, UK) $20 \mathrm{mg} \mathrm{kg}^{-1}$ intravenously (IV) and meloxicam (Metacam; Boehringer Ingelheim, UK) $0.2 \mathrm{mg} \mathrm{kg}^{-1}$ IV. Fentanyl (Fentanyl citrate; Martindale Laboratories, UK) IV $10 \mathrm{mcg} \mathrm{kg}^{-1}$ hour $^{-1}$ and lidocaine (Lidocaine $\mathrm{HCl} 2 \%$; Hameln Pharmaceuticals, UK) IV $30 \mathrm{mcg} \mathrm{kg}^{-1}$ minute ${ }^{-1}$ were used during the surgical procedure.
2.2. Surgery. The dog was placed in left lateral recumbency to allow a right-sided approach to the thoracic cavity. An Arndt endobronchial blocker, $7 \mathrm{fr}$ (Cook Medical, USA), was placed under endoscopic visualisation via the endotracheal tube adaptor (Cook Medical, USA) using the looped guide wire into the right caudal lobe bronchus, making sure it was caudal to the right cranial bronchus and the cuff inflated. The right medial, accessory, and caudal lobes were blocked using this technique. Ventilatory and respiratory parameters were $f_{R} 15 \mathrm{bpm}, V_{T} 185 \mathrm{~mL}$ resulting in a PIP of $12 \mathrm{~cm} \mathrm{H}_{2} \mathrm{O}$ and a dynamic lung compliance $35 \mathrm{~mL} \mathrm{~cm} \mathrm{H}_{2} \mathrm{O}^{-1}$. The thorascopic instrument portals were placed percutaneously in the right lateral thoracic wall and direct visualisation of the lung lobe abscess was possible. Arterial blood gas analysis taken 10 minutes after commencement of thoracoscopy and 30 minutes after the start of SLV showed a reduction in arterial oxygen partial pressure $\left(\mathrm{PaO}_{2}\right)$ from $400 \mathrm{mmHg}$ to $275 \mathrm{mmHg}$ corresponding to a reduction in $\mathrm{PaO}_{2}: \mathrm{FiO}_{2}$ from 444 to 306 and an increase in F-Shunt from 17.4 to $23.7 \%$. $f_{R}$ was increased to $17 \mathrm{bpm}$. Dynamic lung compliance had decreased to $20 \mathrm{~mL} \mathrm{~cm} \mathrm{H}_{2} \mathrm{O}^{-1}$.

Measured cardiovascular parameters during SLV remained stable, with HR $60 \mathrm{bpm}$ and mean invasive blood pressure $70 \mathrm{mmHg}$. There was minimal sympathetic response to both thoracoscopy and thoracotomy.

After 20 minutes of thoracoscopy and 40 minutes of SLV, the surgeon made the decision that it would not be possible to remove the abscess by this approach due to adhesions of the lung to the diaphragm, and conversion to a standard lateral thoracotomy was made. The EBB cuff was deflated and two-lung ventilation initiated. The surgeon also felt the inflation of the cranial lung lobe reduced visibility within the thorax. On opening of the thoracic cavity, a positive endexpiratory pressure (PEEP) of $3 \mathrm{~cm} \mathrm{H}_{2} \mathrm{O}$ was applied. Arterial blood gas analysis showed a $\mathrm{PaO}_{2}$ of $300 \mathrm{mmHg}$ corresponding to a $\mathrm{PaO}_{2}: \mathrm{FiO}_{2}$ of 333. Cardiovascular parameters were within normal limits. No alterations to the ventilatory settings were made. The lung lobe abscess was successfully removed with this approach, and the dog made an uneventful recovery from anaesthesia.

Postoperatively, analgesia was provided with methadone $0.3 \mathrm{mg} \mathrm{kg}^{-1} \mathrm{IM}$ as required, meloxicam $0.1 \mathrm{mg} \mathrm{kg}^{-1}$ per os, continuation of the lidocaine IV infusion for 24 hours, and intrapleural bupivacaine $1 \mathrm{mg} \mathrm{kg}^{-1}$ every 6 hours. Intercostal nerve blocks were performed in three rib spaces cranial and caudal to the incision. The dog progressed well and was discharged after 5 days.

\section{Discussion}

In this case, the EBB was successfully placed and used to achieve SLV. SLV cannot be achieved with any of the other techniques because the DLT, endobronchial tube, or EZblocker cannot easily be advanced distal enough to the carina to selectively block a specific lung lobe. In human anaesthesia, SLV has been shown to have beneficial effects not only during anaesthesia but also in the postoperative period compared to the use of OLV. Selective lung ventilation was associated with improved intra- and postoperative arterial 
oxygenation, a lower shunt fraction $\left(Q_{s} / Q_{t}\right)$, and a shorter hospital stay [9].

Selective lung ventilation may be required for certain thorascopic procedures. In healthy dogs, the effect of OLV on $\mathrm{PaO}_{2}$ and arterial oxygen content $\left(\mathrm{CaO}_{2}\right)$ was not deemed to be of any biological or clinical significance, although it does increase $Q_{s} / Q_{t}$ due to nonventilation of a portion of lung in open chest thoracotomy [5]. These changes have been associated with a small increase in cardiac output [10]. The use of SLV may reduce the resultant $Q_{s} / Q_{t}$ and have a lesser impact on oxygenation.

Selective lung ventilation was chosen in this case to minimise the reduction in $\mathrm{PaO}_{2}$ associated with OLV [5] and because only the caudal lung lobe was diseased and required resection. A reduction in $\mathrm{PaO}_{2}$ was observed after commencing SLV, reducing the $\mathrm{PaO}_{2}: \mathrm{FiO}_{2}$ ratio from 444 to 306 but with no resultant change in any monitored cardiovascular parameters including $\mathrm{SpO}_{2}$. However, the reduction in $\mathrm{PaO}_{2}$ in this case was 31\% (444 to $306 \mathrm{mmHg}$ ) compared to $50 \%$ (361 to $184 \mathrm{mmHg}$ ) in a previous report of OLV [5]. The arterial oxygenation variables recorded in this case suggest SLV may be better at preserving $\mathrm{PaO}_{2}$ than OLV. The oxygen indices recorded in this case are limited by the short duration of SLV, and we do not know what changes would occur if it was performed for a longer period of time.

In this case, we chose to use the oxygen index, F-shunt to illustrate changes associated with $Q_{s} / Q_{t}$ during SLV because it can be easily calculated. For these calculations, there is no need to place a pulmonary artery catheter, only an arterial catheter is required to allow sampling for haemoglobin concentration, $\mathrm{PaO}_{2}$ and $\mathrm{PaCO}_{2}$. The usefulness of different oxygen tension indices to predict shunt fraction varies amongst studies. This is in direct contrast to another study in which F-Shunt and $\mathrm{PaO}_{2}: \mathrm{FiO}_{2}$ were good estimates of shunt fraction in sheep [11]. The human literature reports values for $\mathrm{PaO}_{2}: \mathrm{FiO}_{2}$ of less than 200 in acute respiratory distress syndrome and less than 300 in acute lung injury [12]; therefore, in this case the reduction in $\mathrm{PaO}_{2}$ : $\mathrm{FiO}_{2}$ was not thought to be of clinical significance. This conclusion was also reached when we looked at the increase in calculated FShunt (17.4 to $23.7 \%$ ), which was within the range reported by Araos et al. [11] and Briganti et al. [13] in sheep and horses, respectively. This is in comparison to the increase in $Q_{s} / Q_{t}$ of 17 to $30 \%$ reported with OLV [5]. Therefore, we interpret this as not being of clinical significance. However, this increase in shunt most likely explains the reduction in $\mathrm{PaO}_{2}$ observed.

Lung compliance (CL) reduced from 35 to $20 \mathrm{~mL}$ $\mathrm{cm} \mathrm{H}_{2} \mathrm{O}^{-1}$ after commencement of thoracoscopy. Unfortunately, we do not have a record of CL before SLV commenced. Lung compliance shortly after two-lung ventilation was restarted was $30 \mathrm{~mL} \mathrm{~cm} \mathrm{H}_{2} \mathrm{O}^{-1}$.

Hypoxic pulmonary vasoconstriction (HPV) [10] is a process that aids in reducing pulmonary shunt. Its effect is reduced by a number of factors especially the use of volatile anaesthetic agents. Isoflurane was used in this case for maintenance of anaesthesia and is, therefore, likely to have reduced the HPV response. Isoflurane blocks HPV in a dosedependent manner and in this case the adjunct analgesic agents, fentanyl and lidocaine, were utilised with the aim of reducing the end tidal isoflurane concentration. It may have been more appropriate to have used total intravenous anaesthesia to minimise both the blunting of HPV and the cardiorespiratory depressant effects of the volatile anaesthetic agents, but we still used isoflurane because of performing SLV and not OLV.

No change in $\mathrm{PE}^{\prime} \mathrm{CO}_{2}$ was observed during this procedure with a marginal increase of $\mathrm{PaCO}_{2}$. This can be explained by the small increase in alveolar dead space fraction $(\mathrm{Vd} / \mathrm{Vt})$ of 0.18 to 0.20 by SLV $\left(\mathrm{Vd} / \mathrm{Vt}=\left(\mathrm{PaCO}_{2}-\right.\right.$ $\left.\left.\mathrm{PE}^{\prime} \mathrm{CO}_{2}\right) / \mathrm{PaCO}_{2}\right)$, both though remaining within the reference range in the human literature [14].

Positive end expiratory pressure was not used in this case during SLV due to concern about possible reduction in cardiac output $\left(Q^{\prime}\right)$. This is particularly of concern in a closed chest situation, where it could cause overdistension of alveoli when the administered tidal volume remains as for twolung ventilation. There was also a possibility that it would reduce visibility and surgical access. It was only initiated when the procedure was converted to a thoracotomy. The use of PEEP has been shown to have a beneficial effect on $\mathrm{PaO}_{2}$, the resultant alveolar-arterial oxygen gradient and $Q_{s} / Q_{t}$ in dogs undergoing closed chest thoracoscopy with OLV and no adverse effect on $Q[8,15]$. It is, therefore, not known if the use of PEEP may have prevented the reduction in $\mathrm{PaO}_{2}$ observed after commencing SLV in this case. After conversion to thoracotomy, the $\mathrm{PaO}_{2}$ increased marginally, which could be accounted for by the use of PEEP, although no recruitment manoeuvre was performed.

Unfortunately in this case, the use of SLV did not provide the required surgical conditions for completion of the partial lung lobectomy, although no problems were encountered with its use. One of the most common reasons reported for conversion to a thoracotomy is poor visualisation within the thorax, primarily as a result of movement of the endobronchial cuff [7], which we did not observe in this case.

The nonsteroidal anti-inflammatory, meloxicam was also given as part of the multimodal approach to analgesia in this case. It may have been more appropriate to administer it after the procedure, especially as haemorrhage and periods of hypotension were possible, though not observed complications.

This paper documents the use of an EBB and SLV with continued ventilation of the right cranial lung lobe. EBB placement is a straightforward technique to learn, but due to problems with visualisation in this case further studies are required to show any benefits of SLV over OLV.

\section{Conflict of Interests}

All authors have no known conflict of interests.

\section{References}

[1] E. Monnet, "Interventional thoracoscopy in small animals," Veterinary Clinics of North America-Small Animal Practice, vol. 39, no. 5, pp. 965-975, 2009. 
[2] P. J. Walsh, A. M. Remedios, J. F. Ferguson, D. D. Walker, S. Cantwell, and T. Duke, "Thoracoscopic versus open partial pericardectomy in dogs: Comparison of postoperative pain and morbidity," Veterinary Surgery, vol. 28, no. 6, pp. 472-479, 1999.

[3] C. Adami, S. Axiak, U. Rytz, and C. Spadavecchia, "Alternating one lung ventilation using a double lumen endobronchial tube and providing CPAP to the non-ventilated lung in a dog," Veterinary Anaesthesia and Analgesia, vol. 38, no. 1, pp. 70-76, 2011.

[4] K. Ruetzler, G. Grubhofer, W. Schmid et al., "Randomized clinical trial comparing double-lumen tube and EZ-Blocker for single-lung ventilation," British Journal of Anaesthesia, vol. 106, no. 6, pp. 896-902, 2011.

[5] S. T. Kudnig, E. Monnet, M. Riquelme, J. S. Gaynor, D. Corliss, and M. D. Salman, "Effect of one-lung ventilation on oxygen delivery in anesthetized dogs with an open thoracic cavity," American Journal of Veterinary Research, vol. 64, no. 4, pp. 443-448, 2003.

[6] S. T. Kudnig, E. Monnet, M. Riquelme, J. S. Gaynor, D. Corliss, and M. D. Salman, "Effect of positive end-expiratory pressure on oxygen delivery during 1-lung ventilation for thoracoscopy in normal dogs," Veterinary Surgery, vol. 35, no. 6, pp. 534$542,2006$.

[7] J. H. Campos, "An update on bronchial blockers during lung separation techniques in adults," Anesthesia and Analgesia, vol. 97, no. 5, pp. 1266-1274, 2003.

[8] M. Mosing, I. Iff, and Y. Moens, "Endoscopic removal of a bronchial carcinoma in a dog using one-lung ventilation," Veterinary Surgery, vol. 37, no. 3, pp. 222-225, 2008.

[9] J. Ye, M. N. Gu, C. Q. Zhang, K. C. Cai, and R. J. Cai, "Effects of selective left lower lobar blockade by Coopdech endobronchial blocker tube on intrapulmonary shunt and arterial oxygenation: a comparison with double-lumen endobronchial tube," Nan Fang Yi Ke Da Xue Xue Bao, vol. 29, no. 11, pp. 22442247, 2009.

[10] M. Riquelme, E. Monnet, S. T. Kudnig et al., "Cardiopulmonary changes induced during one-lung ventilation in anesthetized dogs with a closed thoracic cavity," American Journal of Veterinary Research, vol. 66, no. 6, pp. 973-977, 2005.

[11] J. Araos, M. P. Larenza, V. DeMonte et al., "Evaluation of different oxygenation indices for estimation of intrapulmonary venous admixture at different inspiratory oxygen fractions in anesthetized sheep," in Proceedings of the Spring Meeting of the Association of Veterinary Anaesthetists, p. 75, Bari, Italy, 2011.

[12] S. P. Pilbeam, "Oxygenation and acid-base evaluation," in Mechanical Ventilation: Physiological and Clinical Applications, S. P. Pilbeam and J. M. Cairo, Eds., pp. 1-13, Mosby Elsevier, 2006.

[13] A. Briganti, D. A. Portela, M. Sgorbini et al., "Comparison of different oxygenation indices for the estimation of intrapulmonary shunt in horses under general anaesthesia," in Proceedings of the Spring Meeting of the Association of Veterinary Anaesthetists, p. 129, Bari, Italy, 2011.

[14] S. P. Pilbeam, "Appendix B," in Mechanical Ventilation: Physiological and Clinical Applications, S. P. Pilbeam and J. M. Cairo, Eds., pp. 601-606, Mosby Elsevier, 2006.

[15] M. Riquelme, E. Monnet, S. T. Kudnig et al., "Cardiopulmonary effects of positive end-expiratory pressure during one-lung ventilation in anesthetized dogs with a closed thoracic cavity," American Journal of Veterinary Research, vol. 66, no. 6, pp. 978-983, 2005. 

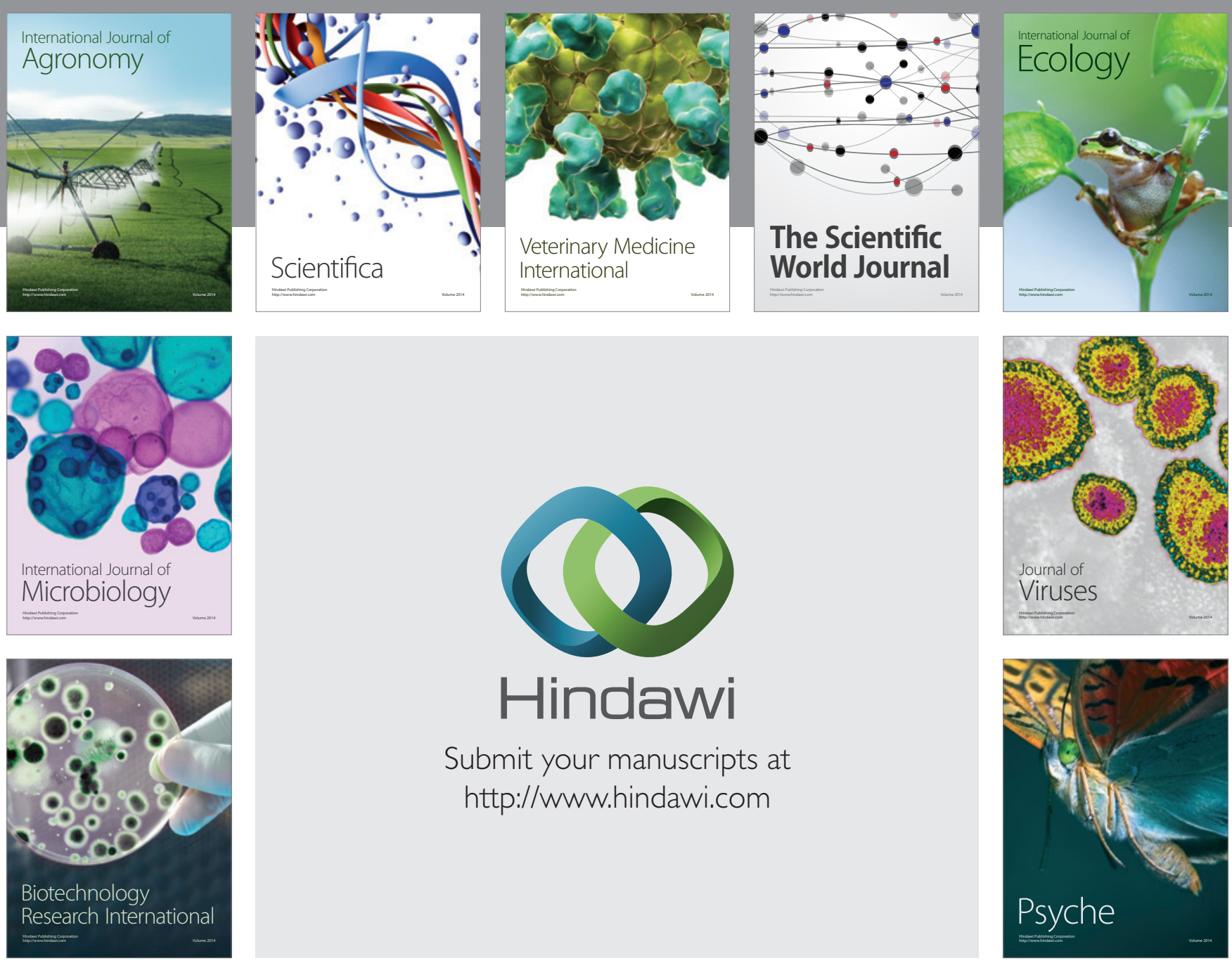

Submit your manuscripts at

http://www.hindawi.com
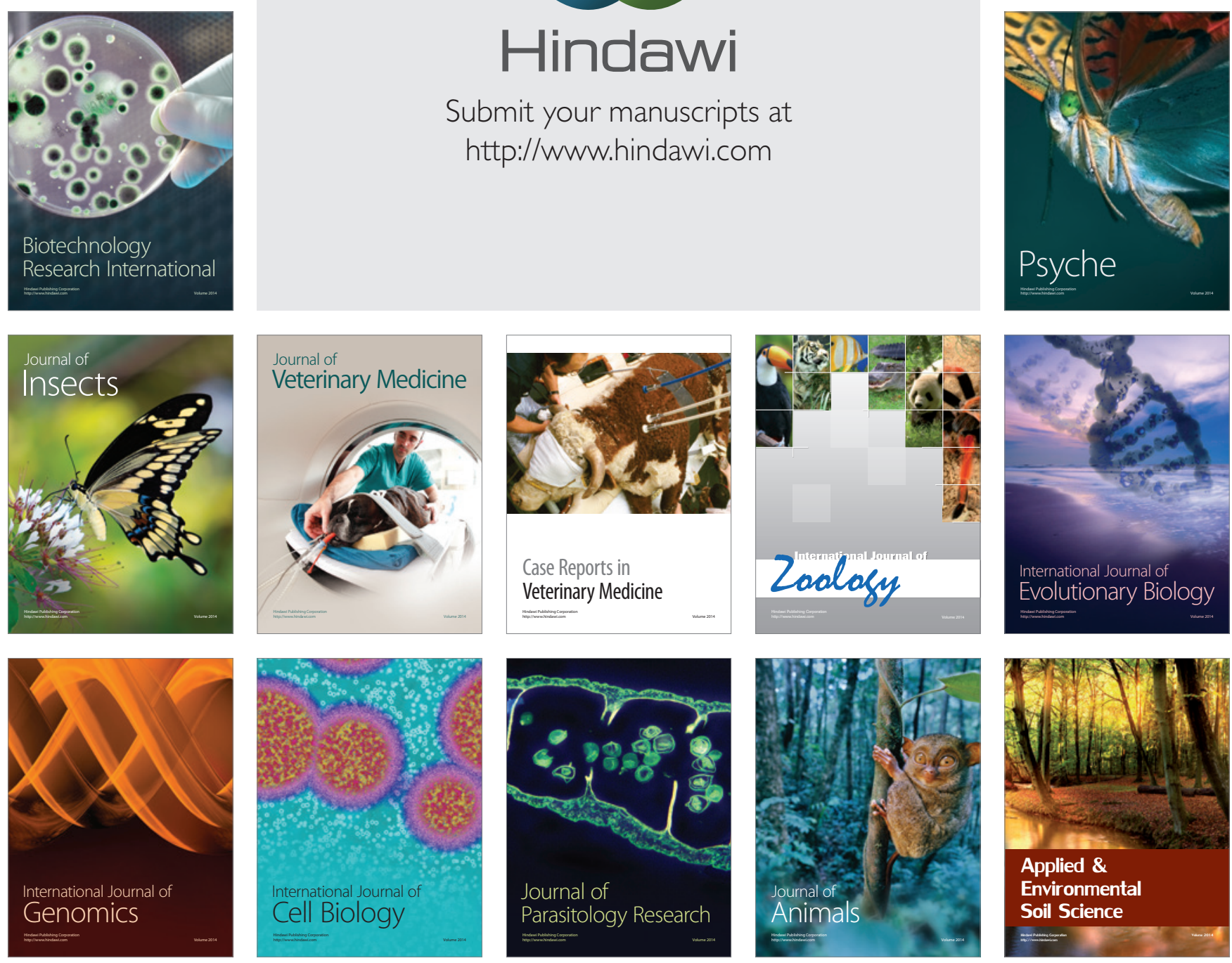